\title{
Three-dimensional printing technology for treatment of intracranial aneurysm
}

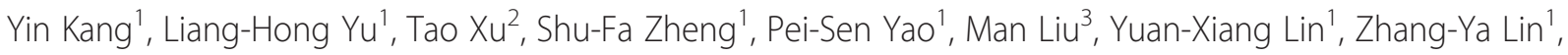 \\ Xiao-Min Fan ${ }^{3}$ and De-Zhi Kang ${ }^{1 *}$
}

\begin{abstract}
Background: The development of three-dimensional (3D) printing technology provides a new method for surgical treatment, but currently there are few reports on its application in the treatment of aneurysm. The aim of the present study was to explore the materials and methods of fabricating 3D printed individual aneurysm model and its value in the treatment of intracranial aneurysm.

Methods: Twenty-four patients with intracranial aneurysm diagnosed by CTA who had undergone operation in our hospital were analyzed retrospectively. CTA Data collected at the time of surgery was used for reconstruction. Soft Mimics 17.0 was used to reconstruct the thin layer CTA scan data into 3D image and the final data was sent to the 3D printer for fabricating the model. We compared the proposed 3D printed model-based preoperative plan and the actual approach used in the surgery based on CTA data to evaluate the value of the 3D printed model in preoperative planning, and picked out the materials which were more suitable for the clinic.

Results: Twenty-four aneurysm models with high degree of reality were fabricated successfully with 3D-printing technology. The patients' blood vessels, skulls and aneurysms were printed into the reality model at a ratio of 1:1. It is reported that the soft material-based, 3D printed vascular and aneurysm model more closely resembled the characteristics of the real blood vessels, thus provides a better simulation compared to the plaster-based model. Compared with the original operation plan, 3D printed model could be used for pre-operative aneurysm clip selection, and provide more intuitive information in selection of operational approach.

Conclusions: 3D printed model can be used as an operational physical model to design operative schemes, choose the best operative paths and select suitable aneurysm clips by its high simulation degree and individualized characteristics. The model is helpful for surgical planning, especially for the preoperative plan of treating refractory multiple aneurysms and giant aneurysms.
\end{abstract}

Keyword: 3D printed model, Intracranial aneurysm, Operation design

\section{Background}

Intracranial aneurysm with and without subarachnoid hemorrhage (SAH) is an important health problem: The overall incidence rate is about 9 cases, and can be as high as 20 per 100,000 in some countries [1]. Microsurgical clipping is the standard technique for cerebral aneurysm surgery, and a suitable operative plan is the key for the success of this operation [2, 3]. Preoperative imaging cannot clearly show the complicated anatomic relationship between the aneurysm and surrounding cranial nerves,

\footnotetext{
* Correspondence: kdz99988@sina.com

${ }^{1}$ Department of Neurosurgery, The First Affiliated Hospital, Fujian Medical

University, Fuzhou 350005, Fujian Province, China

Full list of author information is available at the end of the article
}

vasculature, and other critical anatomical structures clearly to the surgeon. The development of three-dimensional (3D) printing technology provides a new method for surgical treatment of aneurysm. This technology has been widely used in oral surgery and orthopedics [4-6], but currently there are few reports on its application in the treatment of aneurysm. In this study, 24 patients with intracranial aneurysm diagnosed by CT angiography (CTA) who had undergone operation in our hospital were analyzed retrospectively, the materials and methods of fabricating $3 \mathrm{D}$ printed individual aneurysm model were explored, and the value of 3D printed model and its value in the treatment of intracranial aneurysm was evaluated. 


\section{Methods}

\section{Patient information}

The study protocol was approved by the ethics committee of the First Affiliated Hospital of Fujian Medical University. All patients provided written informed consent. Twenty-four patients with intracranial aneurysm diagnosed by CTA had been surgically treated in the department of neurosurgery, First Affiliated Hospital of Fujian Medical University. There were 11 male and 13 female patients between the ages of 39 and 69 years old. A total of 49 aneurysms were confirmed by CT angiography, with 12 cases of multiple aneurysms and 6 cases of giant aneurysm. Of the 49 aneurysms, 5 were located in the anterior cerebral artery (ACA), 5 in the anterior communicating artery (ACoA), 15 in the middle cerebral artery (MCA), 8 in the posterior communicating artery (PCoA), 8 in the carotid artery (CA), 4 in the ophthalmic artery (OphtA), 1 in the anterior choroidal artery (AChA), 1 in the basilar artery (BA), and 3 in the vertebral artery (VA) (Table 1 ).

\section{Aneurysm model}

\section{Generation and post-processing of CTA data}

Dynamic CTA images were procured using a 320-detector row dynamic volume CT scanner (Aquilion One, Toshiba Medical Systems, Nasu, Japan). The scanning parameters were as following: scan range, $16 \mathrm{~cm}$; gantry rotation time, $350 \mathrm{~s}$; slice thickness, $0.5 \mathrm{~mm}$; field of view (FOV), $240 \mathrm{~mm}$; tube potential, $120 \mathrm{kV}$; and tube current, $300 \mathrm{~mA}$. During the scanning process, layer thickness $(0.5 \mathrm{~mm})$ and interval $(0.5 \mathrm{~mm})$ reconstruction were obtained. Images were exported in standard digital imaging and communication in medicine (DICOM) format to the 3D calculation software, Soft Mimics17.0 (Materialise, Belgium). Soft tissue and brain tissue around the skull was removed. The vascular and bone area was segmented by the software, and the virtual 3D angiogram was generated. The skull, intracranial artery and aneurysm were distinguished by different colors. Data from the segmented area was transformed into a STereoLithography (STL) format, which was used in the rapid prototyping machine.

\section{Manufacturing of aneurysm 3D printing model}

The STL format file was input into the $3 \mathrm{D}$ printer (Objet Connex350 3D printer Objet Technologies Ltd, Rehovot, Israel) to fabricate the model. Originally, plaster was used to fabricate a solid model, including skull, blood vessels and aneurysm. It turned out that solid models were still too rigid and brittle to simulate the human blood vessels. An appropriate aneurysm model requires the use of three different materials to create the solid skull, flexible blood vessels, and the hollow aneurysm. To this end, Objet Connex500 3D printer, which offers the ability to work with any mix of rigid and flexible materials, was
Table 1 Summary of 24 patients identification

\begin{tabular}{|c|c|c|c|c|c|}
\hline Patient & Sex & $\begin{array}{l}\text { Age } \\
\text { (years) }\end{array}$ & $\begin{array}{l}\text { Hunt-Hess } \\
\text { classification } \\
\text { score }\end{array}$ & Lesion & Rupture \\
\hline 1 & M & $52 y$ & $\|$ & L-MCA & Y \\
\hline 2 & M & $56 y$ & IV & $\mathrm{ACOA}$ & Y \\
\hline 3 & $\mathrm{~F}$ & $64 y$ & । & $\mathrm{ACOA}$ & N \\
\hline 4 & M & $47 y$ & । & R-MCA & N \\
\hline 5 & $\mathrm{~F}$ & $52 y$ & $\|$ & L-MCA*2、R-OphtA & Y \\
\hline 6 & $\mathrm{~F}$ & $64 y$ & $\|$ & $\begin{array}{l}\text { L-PCOA、R-PCOA、 } \\
\text { L-ICA }\end{array}$ & Y \\
\hline 7 & M & $57 y$ & । & ACOA、L-MCA & N \\
\hline 8 & $\mathrm{~F}$ & $54 y$ & $\|$ & $\begin{array}{l}\text { L-MCA、R-MCA、 } \\
\text { L-OphtA、R- OphtA }\end{array}$ & Y \\
\hline 9 & $\mathrm{~F}$ & $53 y$ & $\|$ & L-PCOA、R-MCA & Y \\
\hline 10 & $\mathrm{~F}$ & $51 y$ & III & $\begin{array}{l}\text { L-VA、BA、R-MCA、 } \\
\text { R-ACA }\end{array}$ & Y \\
\hline 11 & $\mathrm{~F}$ & $55 y$ & $\|$ & L-PCoA、R-PCoA & Y \\
\hline 12 & $\mathrm{~F}$ & $58 y$ & $\|$ & L-ICA、R-ICA & Y \\
\hline 13 & M & $57 y$ & $\|$ & $\begin{array}{l}\text { R-PCOA、R-AChA、 } \\
\text { L-ICA、L-MCA、L-ACA*2 }\end{array}$ & Y \\
\hline 14 & $\mathrm{~F}$ & $64 y$ & $\|$ & $R-M C A^{*} 2 、 L-A C A$ & Y \\
\hline 15 & $\mathrm{~F}$ & $69 y$ & $\|$ & L-ICA、R-ICA & Y \\
\hline 16 & $\mathrm{~F}$ & $64 y$ & $\|$ & R-PCoA、L-OphtA & Y \\
\hline 17 & M & $56 y$ & I & R-MCA & N \\
\hline 18 & M & $58 y$ & I & $\mathrm{ACOA}$ & N \\
\hline 19 & M & $55 y$ & I & R-MCA & N \\
\hline 20 & M & $59 y$ & 1 & $\mathrm{ACOA}$ & N \\
\hline 21 & M & $47 y$ & $\|$ & R-ICA & Y \\
\hline 22 & $\mathrm{~F}$ & $58 y$ & $\|$ & R-ICA & Y \\
\hline 23 & $\mathrm{~F}$ & $42 y$ & $\|$ & L-VA、R-MCA、R-PCoA & Y \\
\hline 24 & M & $39 y$ & IV & R-VA & Y \\
\hline
\end{tabular}

$A C A$ anterior cerebral artery, $A C O A$ anterior communicating artery, MCA middle cerebral artery, $P C O A$ posterior communicating artery, $C A$ carotid artery, OphtA ophthalmic artery, $A C h A$ anterior choroidal artery, BA basilar artery, $V A$ vertebral artery, $R$ right, $L$ left, $F$ female, $M$ male

selected for this application. A light-cured resin material was chosen for the bone and a different flexible resin material for the aneurysm. Twenty-four new models were fabricated with this method.

\section{Simulation}

After 3D model fabrication, two experienced vascular neurosurgeons proposed a desired surgical approach for each model. When deciding the surgical approach, especially in patients with complex, multiple and vertebrobasilar aneurysms, the 3D model was used to simulate access and clipping to the aneurysms. The modelbased preoperative plan was then compared with the 
CTA-based surgical plan for evaluating the value of the model in preoperative planning.

\section{Result}

Twenty-four 3D aneurysm models were fabricated and the time required for manufacturing was $20 \mathrm{~h}$ on average. The associated cost of each model is around RMB¥ 3000 to 4000. The models successfully replicated the circle of Willis arteries, the posterior circulation arteries and the structure of skull base including anterior clinoid process $(\mathrm{ACP})$, posterior clinoid process $(\mathrm{PCP})$, sphenoid ridge, basilar clivus, and petrous bone in all cases. Comparison of the location and shape of the aneurysm from both the CTA images and the printed replicas showed good agreement (Fig. 1).

Firstly, two biomodels were created by Plaster-based $3 \mathrm{D}$ printing $(\mathrm{PP})$ technology which was widely used in orthopedics and oral surgery for bone modeling. PP models were rigid and brittle, thus the tortuous and slender intracranial vessel parts broke easily. Furthermore, the aneurismal part was damaged at the weak spot of its basis at the parent vessel after clipping, and clipping simulation was still evaluated to be far from real intraoperative tactile feeling. Therefore we created another 24 biomodels by means of Digital-Light Processing (DLP)3D printing which created the model out of multiple materials. The aneurysm was created using a flexible material that made the aneurysm neck reliable for multiple clipping efforts and the skull was made of a rigid resin material such that a standard craniotomy could be performed on the model. Tactile feedback during the clipping procedure and evaluation of the vessels was judged to be realistic in the DLP model by two vascular neurosurgeons (Fig. 2).

All 24 patients were treated by microsurgery: 45 aneurysms were clipped, 1 was wrapped and the others 3 were not treated by operation. For the ones that were clipped, 2 aneurysms were clipped through the supraorbital keyhole approach, 32 aneurysms were clipped through the pterion keyhole approach, 3 aneurysms were clipped through the trans-frontal keyhole longitudinal fissure approach, 1 aneurysm was clipped through the fronto lateral keyhole approach, 3 aneurysms were clipped through the far-lateral keyhole approach. 1 aneurysm was clipped through the modified pterional keyhole approach and 3 aneurysms were clipped through the pterion-temple association approach. After simulation, the clips and approaches of 5 cases were adjusted. Postoperative CT angiography performed on 24 patients showed 43 aneurysms were satisfactory clipped. According to the modified GOS scores, good result was achieved in 16 patients, mild or severe disability in 5 patients, and death in 3 patients (Table 2). These two neurosurgeons were of the opinion that further refinement of this technology could have a significant impact on neurovascular treatment, particularly in the treatment of complex cases and for educational purposes.

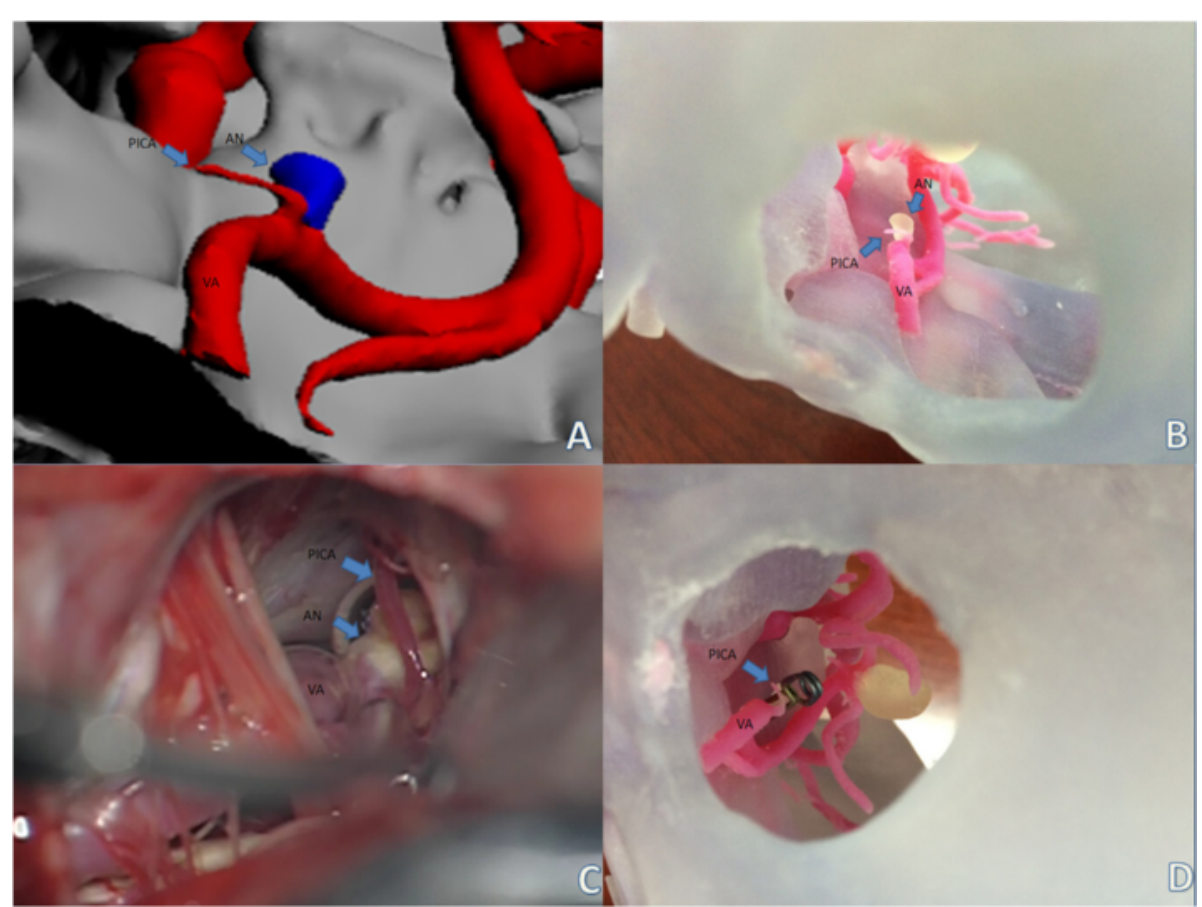

Fig. 1 a: Soft Mimics reconstruction; b: 3D printed model; c: Intraoperative image; d: Clip simulation 


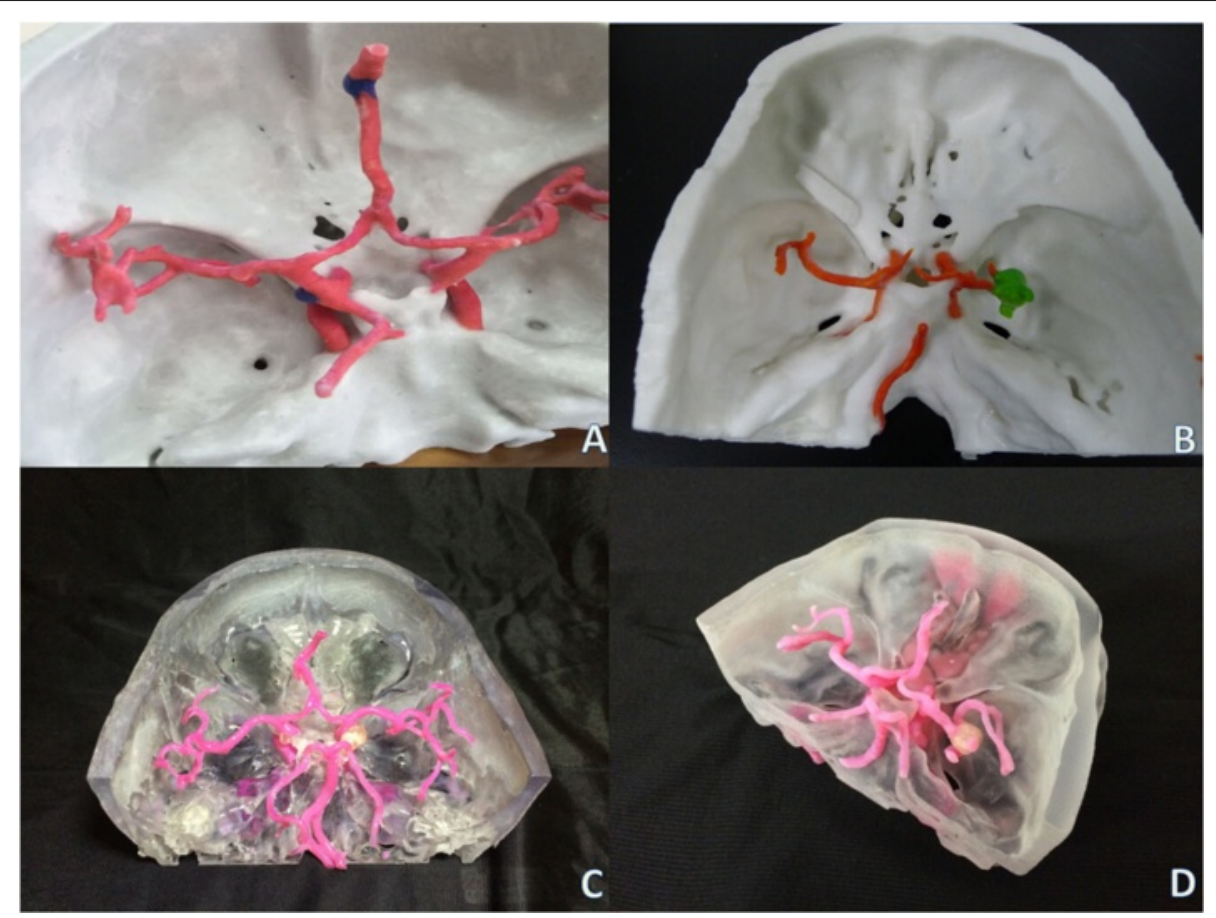

Fig. 2 a and b: Plaster-based 3D printed model; c and $\mathbf{d}$ : Resin-based 3D printed model

\section{Illustrative cases}

\section{Patient 10}

A 51-year-old woman had 4 aneurysms: 1 located in the right middle cerebral artery M1 segment, 1 in the left anterior cerebral artery A3 segment, 1 in top of the basilar artery and 1 in the left vertebral artery. We fabricated the model using her 3D CTA DICOM data. After the measurement, we found the neck of the BA aneurysm was higher than the slope and PCP, and the axis of the aneurysm pointed upwards. So we chose the right supraorbital keyhole approach and performed it on the model. The clipping of the patient's BA and right MCA aneurysms was done through the approach. The VA aneurysm located in the ventral side of brain stem and with the axis pointing upwards. We achieved neck clipping through the left far-lateral keyhole approach, which was the same approach taken during the surgery. The patient's postoperative course was uneventful, and complete neck clipping was confirmed by 3D CTA (Fig. 3).

\section{Patient 15}

A 69-year-old woman had 2 aneurysms in the bilateral internal carotid artery $\mathrm{C} 1$ segment, and the left one was ruptured. The operator clipped bilateral aneurysms through left pterional keyhole approach. Right cerebral hemisphere infarction happened after operation, which was mainly caused by wrongly clipping of the vascular perforating branch around the aneurysm during the surgery. We fabricated the 3D printed model and performed the surgical approach on it. The aneurysm located in L-ICA was exposed clearly through the left pterional keyhole approach, but the one located in R-ICA was not recognized. The axis of the aneurysm pointed to the right side, so the visualization of adjacent structures between the aneurysm and the perforating branches was poor through the left pterional keyhole approach. After simulation, we found that the unilateral pterional keyhole craniotomy was not suitable for the patient, and bilateral pterional keyhole craniotomy was the safer choice (Fig. 4).

\section{Patient 19}

In a 55-year-old man, an unruptured middle cerebral artery aneurysm (M1-2 portion) was discovered incidentally. The long axis of the aneurysm measured to be $22 \mathrm{~mm}$. The patient had undergone aneurysm clipping through the right pterion keyhole approach. During the operation, the surgeon changed the types of aneurysm clips several times before two $10.3 \mathrm{~mm}$ curved clips were finally used. Aneurysm neck clipping was confirmed by 3D CTA after surgery. As viewed from the operative angle, the wide-necked aneurysm located at the bifurcation of M1 and M2 segments. In the 3D printed model simulation, neck clipping was performed successfully using the same clipping strategy (Fig. 5).

\section{Patient 23}

A 42-year-old woman had 3 aneurysms: 1 located in the right vertebral artery which ruptured, and the others in 
Table 2 Summary of surgical therapy and simulation

\begin{tabular}{|c|c|c|c|c|c|}
\hline Patient & Surgical approach & Actual Clipping (Yasargil) & Simulation result & Postoperative CTA & GOS scores \\
\hline 1 & $\begin{array}{l}\text { Left pterion keyhole } \\
\text { approach }\end{array}$ & L-MCA: 10.2 mm curved & Same & Clipping complete & 5 \\
\hline 2 & $\begin{array}{l}\text { Left pterion-temple } \\
\text { association approach }\end{array}$ & $\begin{array}{l}\text { ACoA: } 9.0 \mathrm{~mm} \\
\text { straight + mini clip }\end{array}$ & Same & Clipping complete & 3 \\
\hline 3 & $\begin{array}{l}\text { Right frontolateral } \\
\text { keyhole approach }\end{array}$ & ACoA: fenestrated clip*2 & Same & Clipping complete & 5 \\
\hline 4 & $\begin{array}{l}\text { Right pterion keyhole } \\
\text { approach }\end{array}$ & $\begin{array}{l}\text { R-MCA: } 11.0 \mathrm{~mm} \text { straight } \\
+15.0 \mathrm{~mm} \text { straight } \\
+20.0 \mathrm{~mm} \text { straight }\end{array}$ & $\begin{array}{l}\text { R-MCA: } 15.0 \mathrm{~mm} \text { straight } \\
+20.0 \mathrm{~mm} \text { straight }\end{array}$ & Clipping complete & 5 \\
\hline 5 & $\begin{array}{l}\text { Left pterion keyhole } \\
\text { approach }\end{array}$ & $\begin{array}{l}\mathrm{L}-M C A^{*} 2: 10.2 \mathrm{~mm} \\
\text { curved + fenestrated clip }\end{array}$ & $\begin{array}{l}\text { The aneurysm neck of } \\
\text { R-OphtA can not be exposed }\end{array}$ & $\begin{array}{l}\text { Residual aneurysm of } \\
\text { R-OphtA (The aneurysm neck } \\
\text { is in cavernous sinus) }\end{array}$ & 5 \\
\hline \multirow[t]{2}{*}{6} & $\begin{array}{l}\text { Left pterion keyhole } \\
\text { approach }\end{array}$ & $\begin{array}{l}\text { L-PCOA: } 7.0 \mathrm{~mm} \text { straight; } \\
\text { L-ICA: fenestrated clip }\end{array}$ & \multirow{2}{*}{$\begin{array}{l}\text { The aneurysm of R-ICA was } \\
\text { not recognized through left } \\
\text { pterion keyhole approach }\end{array}$} & \multirow[t]{2}{*}{ Clipping complete } & \multirow[t]{2}{*}{3} \\
\hline & $\begin{array}{l}\text { Right pterion-temple } \\
\text { association approach }\end{array}$ & R-PCoA:9.0 mm straight & & & \\
\hline 7 & $\begin{array}{l}\text { Left pterion keyhole } \\
\text { approach }\end{array}$ & $\begin{array}{l}\text { ACOA: } 7.0 \mathrm{~mm} \text { straight; } \\
\text { L-MCA: } 10.3 \mathrm{~mm} \\
\text { curved + fenestrated clip *2 }\end{array}$ & Same & Clipping complete & 5 \\
\hline \multirow[t]{2}{*}{8} & $\begin{array}{l}\text { Left pterion keyhole } \\
\text { approach }\end{array}$ & $\begin{array}{l}\text { R-MCA: } 6.5 \mathrm{~mm} \text { curved; } \\
\text { L- OphtA: } 11.0 \mathrm{~mm} \text { straight }\end{array}$ & \multirow[t]{2}{*}{$\begin{array}{l}\text { The aneurysm neck of } \\
\text { R-OphtA can not be exposed }\end{array}$} & \multirow{2}{*}{$\begin{array}{l}\text { Residual aneurysm of } \\
\text { R- OphtA (The aneurysm neck } \\
\text { is in cavernous sinus) }\end{array}$} & \multirow[t]{2}{*}{5} \\
\hline & $\begin{array}{l}\text { Right pterion keyhole } \\
\text { approach }\end{array}$ & L-MCA: 10.2 mm curved & & & \\
\hline \multirow[t]{2}{*}{9} & $\begin{array}{l}\text { Right pterion keyhole } \\
\text { approach }\end{array}$ & $\begin{array}{l}\text { R-MCA: } 10.2 \mathrm{~mm} \\
\text { curved }+8.3 \mathrm{~mm} \text { curved }\end{array}$ & \multirow[t]{2}{*}{$\begin{array}{l}\text { The aneurysm of L-PCOA was } \\
\text { not recognized through right } \\
\text { pterion keyhole approach }\end{array}$} & \multirow[t]{2}{*}{$\begin{array}{l}\text { L-CA occlusion (L-CA ruptured } \\
\text { during operation) }\end{array}$} & \multirow[t]{2}{*}{1} \\
\hline & $\begin{array}{l}\text { Left pterion keyhole } \\
\text { approach }\end{array}$ & L-PCoA: fenestrated clip & & & \\
\hline \multirow[t]{3}{*}{10} & $\begin{array}{l}\text { Right supraorbital } \\
\text { keyhole approach }\end{array}$ & $\begin{array}{l}\text { BA: } 20.0 \mathrm{~mm} \text { straight; } \\
\text { R-MCA: } 9.0 \mathrm{~mm} \text { straight }\end{array}$ & \multirow[t]{3}{*}{ Same } & \multirow[t]{3}{*}{ Clipping complete } & \multirow[t]{3}{*}{5} \\
\hline & $\begin{array}{l}\text { Right trans-frontal } \\
\text { keyhole longitudinal } \\
\text { fissure approach }\end{array}$ & R-ACA: $6.5 \mathrm{~mm}$ curved & & & \\
\hline & $\begin{array}{l}\text { Left far-lateral keyhole } \\
\text { approach }\end{array}$ & L-VA: $7.0 \mathrm{~mm}$ straight & & & \\
\hline 11 & $\begin{array}{l}\text { Left pterion keyhole } \\
\text { approach }\end{array}$ & $\begin{array}{l}\text { L-PCoA: } 9.0 \mathrm{~mm} \text { straight; } \\
\text { R-PCOA: } 11.0 \mathrm{~mm} \text { straight }\end{array}$ & Same & Clipping complete & 5 \\
\hline 12 & $\begin{array}{l}\text { Left pterion keyhole } \\
\text { approach }\end{array}$ & $\begin{array}{l}\text { L-ICA: } 6.5 \mathrm{~mm} \text { curved; } \\
\text { R-ICA: } 10.2 \mathrm{~mm} \text { curved *2 }\end{array}$ & Same & Clipping complete & 5 \\
\hline \multirow[t]{2}{*}{13} & $\begin{array}{l}\text { Right pterion keyhole } \\
\text { approach }\end{array}$ & $\begin{array}{l}\text { L-ICA: } 11.0 \text { mm straight; } \\
\text { R-PCoA: Mini clip; R-AChA } \\
\text { Mini clip; L-MCA: } \\
\text { fenestrated clip }\end{array}$ & \multirow[t]{2}{*}{ Same } & \multirow[t]{2}{*}{ Clipping complete } & \multirow[t]{2}{*}{5} \\
\hline & $\begin{array}{l}\text { Right trans-frontal } \\
\text { keyhole longitudinal } \\
\text { fissure approach }\end{array}$ & $\begin{array}{l}\text { L-ACA*2: } 10.2 \mathrm{~mm} \\
\text { curved、 } 7.0 \mathrm{~mm} \text { straight }\end{array}$ & & & \\
\hline 14 & $\begin{array}{l}\text { Right pterion keyhole } \\
\text { approach }\end{array}$ & $\begin{array}{l}\text { R-MCA*2: } 6.5 \mathrm{~mm} \text { curved, } \\
8.3 \mathrm{~mm} \text { curved *2; L-ACA } \\
10.2 \mathrm{~mm} \text { curved }\end{array}$ & Same & Clipping complete & 5 \\
\hline 15 & $\begin{array}{l}\text { Left pterion keyhole } \\
\text { approach }\end{array}$ & $\begin{array}{l}\text { L-ICA: } 11.0 \mathrm{~mm} \text { straight; } \\
\text { R-ICA: fenestrated clip*4 }\end{array}$ & $\begin{array}{l}\text { The aneurysm of R-ICA was } \\
\text { not recognized through left } \\
\text { pterion keyhole approach }\end{array}$ & Clipping complete & 1 \\
\hline 16 & $\begin{array}{l}\text { Left pterion keyhole } \\
\text { approach }\end{array}$ & $\begin{array}{l}\text { R-PCoA: } 6.5 \mathrm{~mm} \text { curved, } \\
\text { L-OphtA: } 7.0 \mathrm{~mm} \text { curved }\end{array}$ & Same & Clipping complete & 5 \\
\hline 17 & $\begin{array}{l}\text { Right pterion keyhole } \\
\text { approach }\end{array}$ & $\begin{array}{l}\text { R-MCA: } 10.3 \text { mm curved } \\
+10.2 \mathrm{~mm} \text { curved }\end{array}$ & Same & Clipping complete & 5 \\
\hline
\end{tabular}


Table 2 Summary of surgical therapy and simulation (Continued)

\begin{tabular}{|c|c|c|c|c|c|}
\hline 18 & $\begin{array}{l}\text { Left pterion keyhole } \\
\text { approach }\end{array}$ & ACoA : $15.0 \mathrm{~mm}$ straight & Same & Clipping complete & 5 \\
\hline 19 & $\begin{array}{l}\text { Right pterion keyhole } \\
\text { approach }\end{array}$ & R-MCA: 10.3 mm curved ${ }^{*} 2$ & Same & Clipping complete & 5 \\
\hline 20 & $\begin{array}{l}\text { Left modified pterional } \\
\text { keyhole approach }\end{array}$ & ACoA: 20.0 mm straight $* 9$ & $\begin{array}{l}\text { Clipping through right } \\
\text { pterional keyhole approach } \\
\text { is satisfied }\end{array}$ & $\begin{array}{l}\text { ACA occlusion (Aneurysm } \\
\text { ruptured during operation) }\end{array}$ & 3 \\
\hline 21 & $\begin{array}{l}\text { Left pterion-temple } \\
\text { association approach }\end{array}$ & L-ICA: $2^{*} 15.0 \mathrm{~mm}$ straight & $\begin{array}{l}\text { L-ICA: } 15.0 \mathrm{~mm} \text { straight } \\
+10.3 \mathrm{~mm} \text { curved }\end{array}$ & Residual neck & 3 \\
\hline 22 & $\begin{array}{l}\text { Right pterion keyhole } \\
\text { approach }\end{array}$ & R-ICA: fenestrated clip & Same & Clipping complete & 5 \\
\hline 23 & $\begin{array}{l}\text { Left far-lateral keyhole } \\
\text { approach }\end{array}$ & $\begin{array}{l}\text { VA: } 10.2 \mathrm{~mm} \text { curved } \\
+8.3 \mathrm{~mm} \text { curved } \\
+6.5 \mathrm{~mm} \text { curved }\end{array}$ & $\begin{array}{l}\text { The bony prominence } \\
\text { may be removed and } \\
\text { bony opening must } \\
\text { extended downward }\end{array}$ & $\begin{array}{l}\text { Residual aneurysms of } \\
\text { anterior circulation } \\
\text { (Reoperation had not } \\
\text { be performed) }\end{array}$ & 4 \\
\hline 24 & $\begin{array}{l}\text { Right far-lateral keyhole } \\
\text { approach }\end{array}$ & R-VA: fenestrated clip & $\begin{array}{l}\text { Bony opening must be } \\
\text { extended downward }\end{array}$ & $\begin{array}{l}\text { VA occlusion (Aneurysm } \\
\text { ruptured during operation) }\end{array}$ & 1 \\
\hline
\end{tabular}

$A C A$ anterior cerebral artery, $A C O A$ anterior communicating artery, $M C A$ middle cerebral artery, $P C O A$ posterior communicating artery, $C A$ carotid artery, OphtA ophthalmic artery, $A C h A$ anterior choroidal artery, BA basilar artery, VA vertebral artery, $R$ right, $L$ left

the anterior circulation. The CTA-based plan was to clip the VA aneurysm through left far-lateral keyhole approach. During the operation, massive bleeding occurred when the neck of aneurysm was dissected. The application of a single curved clip and an additional clip was used to stop the bleeding and to clip the aneurysm. After surgery, the patient suffered an incomplete paralysis of cranial nerve. During simulation, we observed the 3D printed model and found that this VA aneurysm was tightly adhered to the junction between the slope and the petrous bone. This relationship between aneurysm and skull base, was however not recognized during the actual surgery when dissecting the neck of the aneurysm. The surgeons drilled the skull based and estimated how much bone should be removed to expose the aneurysm neck appropriately. It was difficult to apply clips through

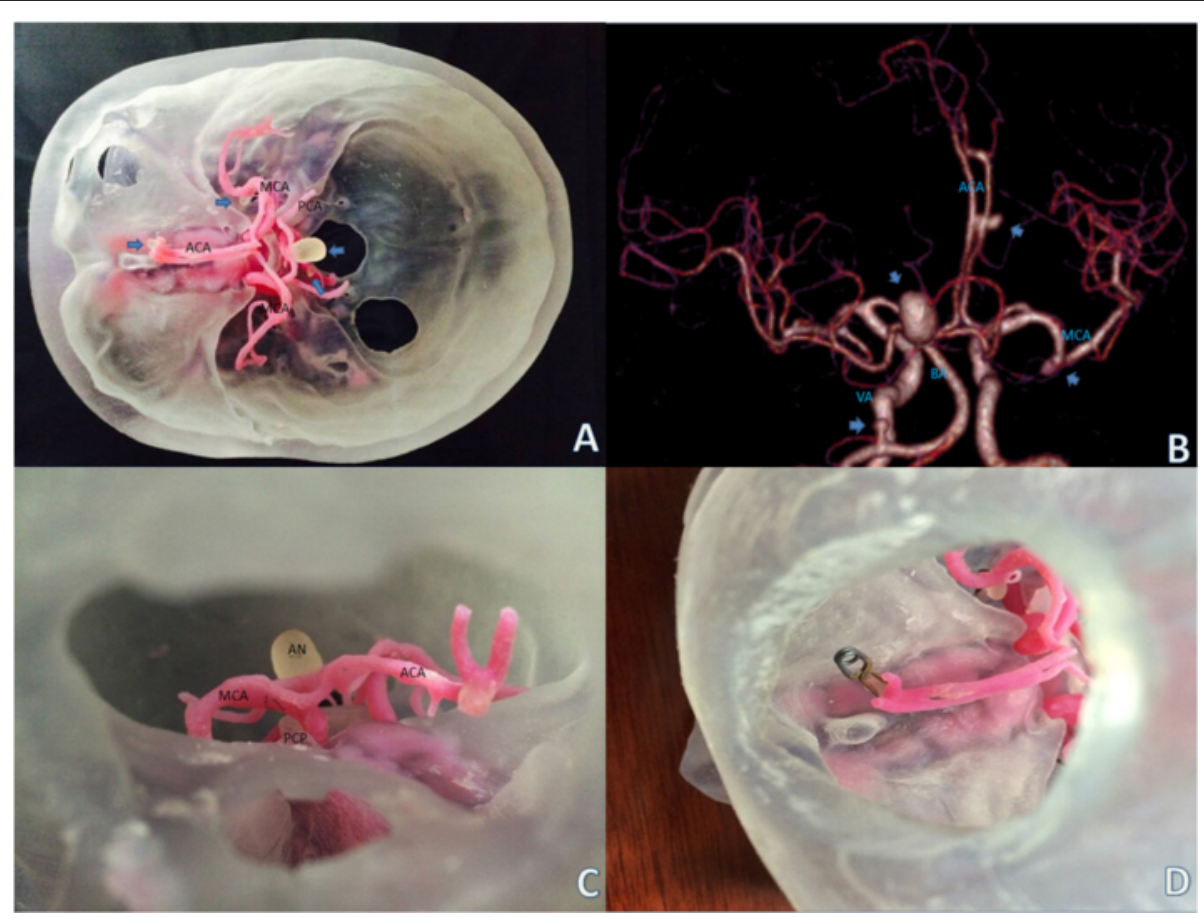

Fig. 3 a: 3D printed model of Patient 10, the arrows point to the aneurysms; $\mathbf{b}$ : CTA image of Patient 10; $\mathbf{c}$ : The neck of the BA aneurysm was higher than the slope and PCP and the neck was exposed clearly through right supraorbital keyhole approach; d: Clip simulation 


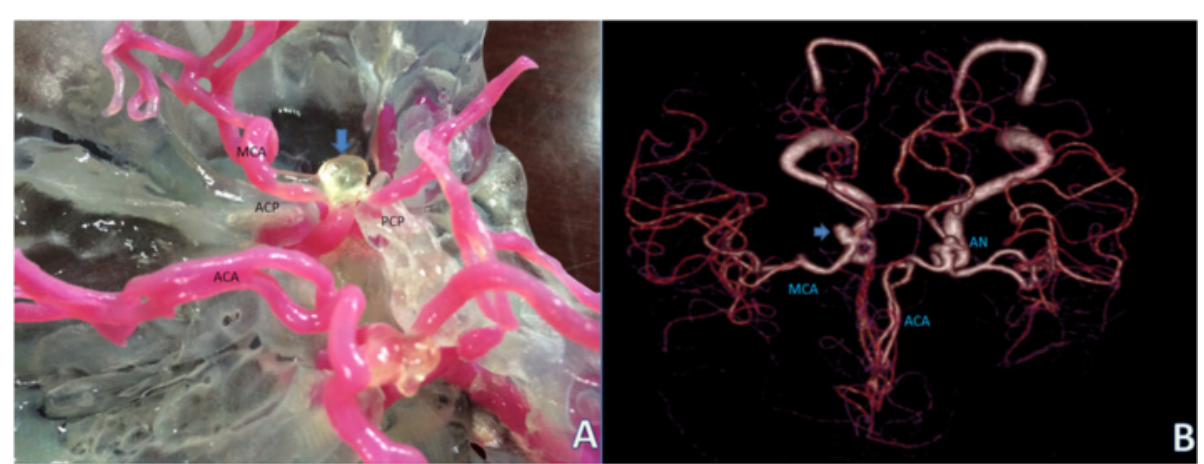

Fig. 4 a: 3D printed model of patient 15, the axis pointing of the aneurysm directed right side, so the visualization of the perforating branches was poor through left pterional keyhole approach; $\mathbf{b}$ : CTA image of Patient 15

the window because the view was initially blocked by a bony prominence above hypoglossal canal. In approaching the aneurysm directly, the bony prominence may be removed and bony opening must extended downward (Fig. 6).

\section{Discussion}

Preoperative imaging has traditionally included MR angiography and/or venography (MRA/MRV), CT angiography and/or venography (CTA/CTV), and digital subtraction angiography (DSA) [7]. Each modality has its benefits and limitations. DSA has traditionally represented the gold standard for elucidating vascular anatomy, but it also carries radiation damage, as well as the cost and time limitations as an invasive procedure. With this methods, it is difficult to acquire the entire image of the skull base, so that the relationship between the aneurysm and the bone cannot clearly present in front of the surgeons. Conventional CTA/CTV offers higher sensitivity and specificity in detecting vascular anatomy than MR-based techniques, but these imaging techniques become more limited in detecting small structures near the skull base due to the interference from adjacent osseous structures. Furthermore, they cannot provide a 3D immersive virtual reality environment for the surgeons [8]. The use of virtual reality technology has been reported in neurosurgery in recent years. The operator can perform segmentation, obtain measurements, and simulate intraoperative viewpoints and the removal of bone and soft tissue in the workstation. But the surgeons cannot use it as a navigation tool during the operation because simulation can only be performed on the computer. Sensory haptic feedback is also different from the real clipping [9-11]. 3D printing technology has important application value in the diagnosis and treatment of aneurysm especially in preoperative surgical rehearsal and neurosurgical training [12-15]. We think its advantages can be reflected in the following aspects:

\section{Efficient and high emulation}

Manufacturing time is always a concern emphasized by researchers. Wurm etc. [12] reported that $40 \mathrm{~h}$ are required to prototype a biomodel and Kimura etc. [13] needed 7 days. On the other hand, with the 3D printing technology, $20 \mathrm{~h}$ is enough for us to collect patient-CTA data, process data into STL and fabricate the model. Less production time and convenient data source make the 3D printing model meet the demand of clinical application. It is fast enough to fabricate an aneurysm model for emergency operations on ruptured cerebral aneurysms. The 3D printed model is easy to carry, so the surgeon can bring it

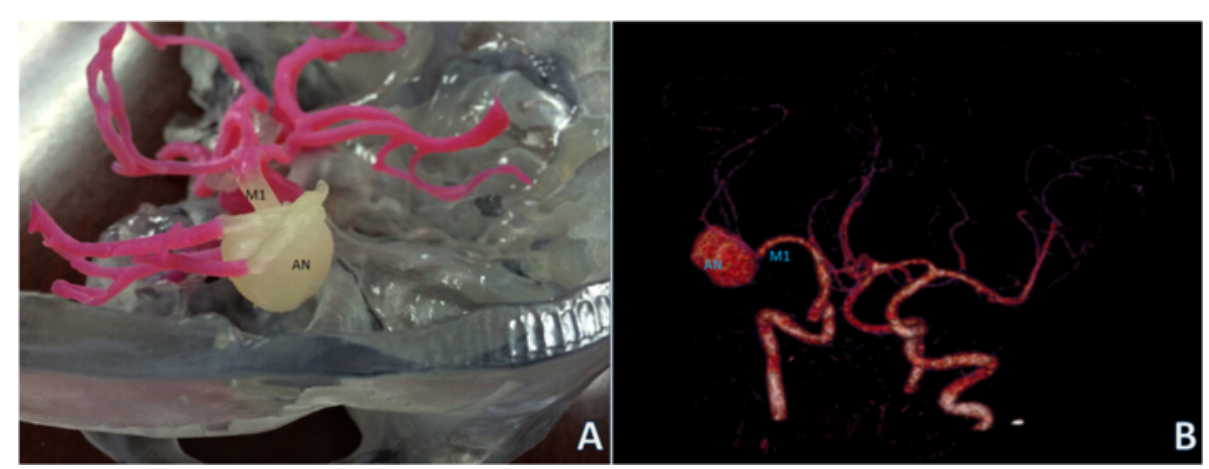

Fig. 5 a: An giant aneurysm was located in middle cerebral artery (M1-2 portion); b: CTA image of Patient 19 


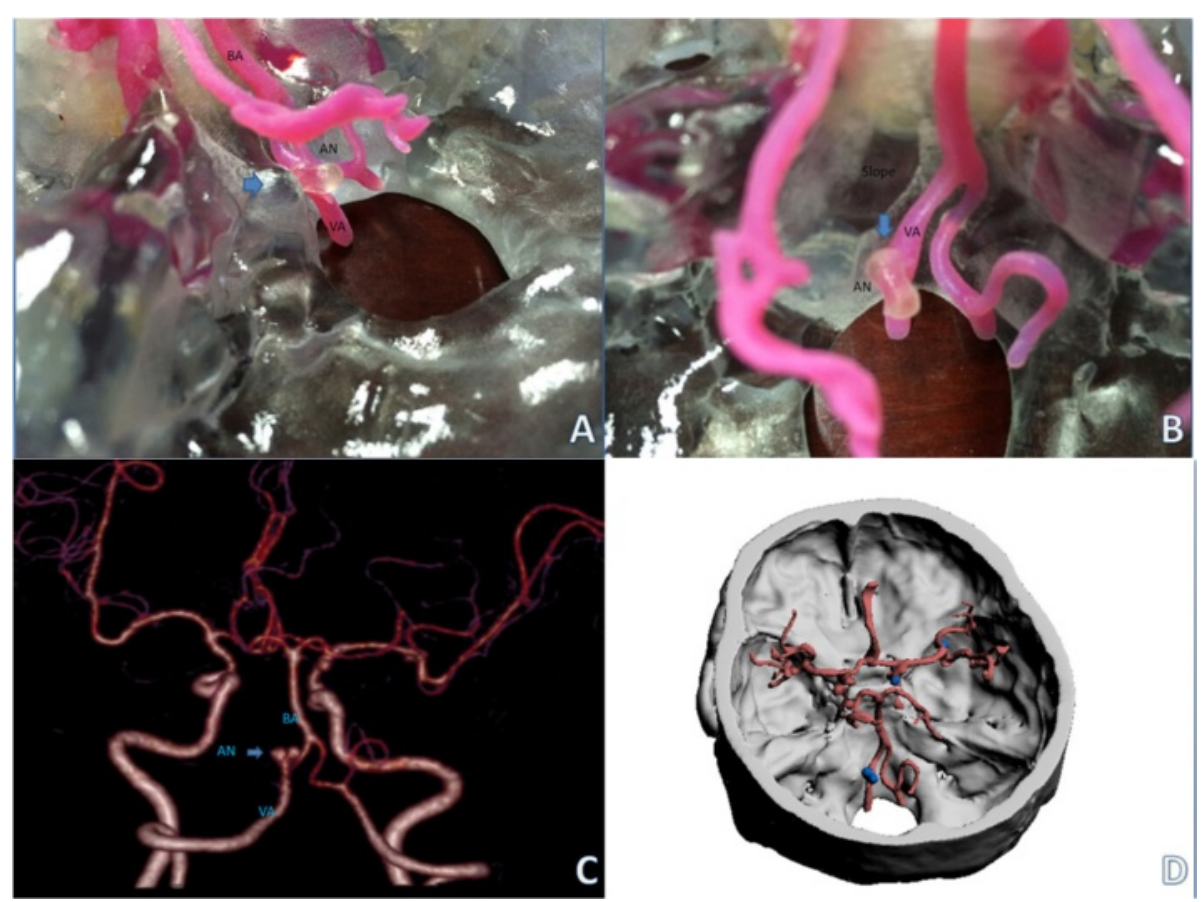

Fig. $\mathbf{6}$ a: The view initially blocked by a bony prominence (arrow) through the bone window; b: The aneurysm was tightly adhered to skull base (arrow); c: CTA image of Patient 23; $\mathbf{d}$ : Soft Mimics reconstruction

into the operation room as a tool for intraoperative navigation. In our study, the high simulation degree of $3 \mathrm{D}$ printed aneurysm model has been proved. The 3D physical model is a tool in understanding the anatomy of the aneurysm (dome size, orientation, and neck size) and the associated vascular structures from every angle.

\section{Simulation for operation}

Our study showed that a model of this nature could be helpful in judging the best surgical approach and selection of the best clip. It can help the surgeons to simulate the operation on the models, including adjusting the head position, drilling the bone, measuring anatomic numerical value and choosing the shortest path to aneurysm. The cerebrovascular model not only allows the surgeon to have a true visual experience, but also a tactile experience which two-dimensional image cannot provide. Posterior circulation aneurysm is adjacent to the brainstem and the clipping operation is performed in a small space, so the choice of operative approach is more important than other parts of the aneurysm in surgery. We have completed 4 models of the patients with verte-brobasilar artery aneurysm, and designed operative approach by grinding occipital bone. It is convenient for the operator to determine the best approach before operation. Neurovascular model also plays a crucial role in the operation of multiple intracranial aneurysms. Treatment of bilateral aneurysms via a unilateral key-hole approach is minimal invasive to patients. The reason of choosing unilateral approach depends on the aneurysm pointing direction [16]. Aneurysms pointing in lateral, anterior or posterior directions are more difficult to clip from the contralateral side, because further inferior extension of the neck may be difficult to recognize. After simulation with $123 \mathrm{D}$ printed models of multiple aneurysms, we could comprehend the anatomy of the aneurysm orientation and neck exposure. The giant aneurysm clipping is a challenging procedure that can only be mastered under the guidance of a seasoned surgeon [17]. The aneurysm clips are always replaced repeatedly during operation, which not only prolongs the operation time, but also causes the risk of premature rupture and inadvertent vessel injury. Our 3D model has a flexible aneurysm part, the aneurysmal neck can be occluded with an actual aneurysm clip after bone grinding as is done during the actual operation. Especially in the giant aneurysm with thrombus which had a wide neck, this model allowed us to estimate how close to the neck we could place the clip without occluding parent vessels and choose the best clip placement. Getting familiar with the complicated structure of the aneurysm and its associated vessels and practicing various techniques of clipping make the surgeon treating the aneurysms confidently during live surgery. Wurm etc. [12] found that tactile feedback during the simulation makes the three-dimensional printed biomodel superior to stereolithography biomodel. We also 
found that procedure and evaluation of the patency of parent and branching vessels was judged to be realistic to real clipping in the DLP-based 3D printed biomodel. Endovascular interventions can be practiced in hollow model that can be coiled, stented, or flow diverted. Namba etc. [18] reported the intracranial aneurysms treated with a microcatheter shape determined by 3D printer hollow aneurysm model and the pre-planned microcatheter shapes demonstrated stability in all except in 1 large aneurysm case. But we could not use the model to test microcatheter in endovascular treatment and evaluate the cerebral hemodynamic changes of aneurysms as the vessel parts of our models were solid.

\section{Applicability}

It has been reported in many articles that the 3D printed model can serve as a valuable teaching resource for trainees $[12,13,19,20]$. The $3 \mathrm{D}$ printed model is also thought to have potential as counseling devices for patients and educational tool for the young doctors. The aneurysm model can create a training environment for junior surgeons to learn surgical approaching, clipping direction, selection of clip, and the shape of the aneurysm in the simulation. Such a model would also inspire neurosurgeons to get new scientific research ideas in the areas of surgical techniques and the shape of aneurysms. [21] Furthermore, training and assessment of surgical skills through the physical models will advance competency training.

\section{Customized fabrication}

We could customize the model to meet different demands of neurovascular surgery. Although we could create the aneurysm models by many methods, the fabrication is time consuming and costly. Fabrication cost and time varied with model size. For example, if we want to fabricate a model for a patient with anterior circulating aneurysm, we could remove posterior cranial fossa when duplicating the geometry of the solid skull, as it takes less time and money to fabricate a model that includes anterior cranial fossa and the circle of Willis arteries than a whole skull model. The modeled hollow vessels without skull could also be used to simulate clipping of a giant or complex aneurysm [22, 23]. When we generate the 3D rotational angiography data, we found that we could fabricate a 3D printed model including skull, vessels, nerve fiber bundle, aneurysm and brain functional areas by advantage integration of different data sources, such as CTA and functional MRI.

\section{Limitations of our models}

In the study, we found some limitations of our 3D printed aneurysm model : 1 . The data source came from CTA image, so the clarity of vascular enhancement will affect the quality of the model. 2 . The accuracy of printing still needs to be improved, especially replica parts of small perforating vessels and terminal blood vessel is still unsatisfactory. 3. Materials are the limiting factor for further refinement of the models today. There are some gaps between the vascular model and the real human blood vessel. 4. The cost of model are expensive, so the high price make it better to be used in the complicated patients. How to improve materials and printing accuracy are the efforts of our ongoing study on 3D printing model.

\section{Conclusions}

The application of 3D printed technology in the field of neurosurgery has been gradually extended. The characteristics of 3D printing aneurysm model including efficiency, high emulation, applicability and customized fabrication for application value in clinical, teaching and scientific research. With the continuous development of the 3D printing technology, complicated brain structure will be shown to neurosurgeon by a physical model, which provides a new method for surgical therapy of intracranial aneurysms.

\begin{abstract}
Abbreviations
3D, three-dimensional; ACA, anterior cerebral artery; AChA, anterior choroidal artery; $\mathrm{ACOA}$, anterior communicating artery; $\mathrm{ACP}$, anterior clinoid process; $\mathrm{BA}$, basilar artery; CA, carotid artery; CTA/CTV, CT angiography and/or venography; DICOM, digital imaging and communication in medicine; DLP, Digital-Light Processing; DSA, STereoLithography; MCA, middle cerebral artery; MRA/MRV, MR angiography and/or venography; OphtA, ophthalmic artery; PCoA, posterior communicating artery; PCP, posterior clinoid process; PP, Plaster-based 3D printing; SAH, subarachnoid hemorrhage; STL, Standard Tessellation Language; $\mathrm{VA}$, vertebral artery
\end{abstract}

\section{Acknowledgements}

We thank Medprin Regenerative Medical Technologies Company Limited for technical support. The study was generously supported by major project of Fujian provincial department of science and technology (No. 2014 YZ0003 and No. 2014 YZO1 to D-ZK), and also sponsored by key clinical specialty discipline construction program of Fujian, PRC.

\section{Funding}

The study was generously supported by major project of Fujian provincial department of science and technology (No. 2014 YZ0003 and No. 2014YZ01 to $\mathrm{D}-\mathrm{ZK})$.

Availability of data and materials

All data generated or analysed during this study are included in this published article.

\section{Authors' contributions}

D-ZK conceived and designed the experiments. YK collected CTA data and drafted the manuscript. Z-YL, S-FZ and P-SY helped to collect the clinic data. L-HY and Y-XL perform simulation on the model. TX, ML and X-MF completed data reconstruction and model manufacture. All authors read and approved the final manuscript.

Competing interests

The authors declare that they have no competing interests.

Consent for publication

Not applicable. 


\section{Ethics approval and consent to participate}

The study protocol was approved by the ethics committee of the First Affiliated Hospital of Fujian Medical University. All patients provided written informed consent.

\section{Author details}

'Department of Neurosurgery, The First Affiliated Hospital, Fujian Medical University, Fuzhou 350005, Fujian Province, China. ${ }^{2}$ Bio-Manufacturing Center, Department of Mechanical Engineering, Tsinghua University, Beijing 100084, China. ${ }^{3}$ Medprin Regenerative Medical Technologies Company Limited, Guangzhou 510000, Guangdong Province, China.

Received: 20 February 2016 Accepted: 27 July 2016

\section{Published online: 18 August 2016}

\section{References}

1. Steiner $T$, Juvela S, Unterberg A, et al. European Stroke Organization guidelines for the management of intracranial aneurysms and subarachnoid haemorrhage. Cerebrovasc Dis. 2013;35:93-112.

2. Fischer $G$, Stadie $A$, Reisch $R$, et al. The keyhole concept in aneurysm surgery: results of the past 20 years. Neurosurgery. 2011;68:45-51. discussion 51.

3. Reisch R, Stadie A, Kockro RA, et al. The keyhole concept in neurosurgery. World Neurosurg. 2013;79(S17):e19-13.

4. Rohner D, Guijarro-Martinez R, Bucher P, et al. Importance of patient-specific intraoperative guides in complex maxillofacial reconstruction. J Craniomaxillofac Surg. 2013:41:382-90.

5. Hurson C, Tansey A, O'donnchadha B, et al. Rapid prototyping in the assessment, classification and preoperative planning of acetabular fractures. Injury. 2007;38:1158-62.

6. Giovinco NA, Dunn SP, Dowling $L$, et al. A novel combination of printed 3dimensional anatomic templates and computer-assisted surgical simulation for virtual preoperative planning in Charcot foot reconstruction. J Foot Ankle Surg. 2012;51:387-93.

7. Bi WL, Brown PA, Abolfotoh M, et al. Utility of dynamic computed tomography angiography in the preoperative evaluation of skull base tumors. J Neurosurg. 2015;123:1-8.

8. Karamessini MT, Kagadis GC, Petsas T, et al. CT angiography with threedimensional techniques for the early diagnosis of intracranial aneurysms. Comparison with intra-arterial DSA and the surgical findings. Eur J Radiol. 2004;49:212-23.

9. Alaraj A, Luciano CJ, Bailey DP, et al. Virtual reality cerebral aneurysm clipping simulation with real-time haptic feedback. Neurosurgery. 2015;11 Suppl 2:52-8.

10. Nakabayashi H, Shimizu K. Stereoscopic virtual realistic surgical simulation in intracranial aneurysms. Neurol India. 2012;60:191-7.

11. Stadie AT, Kockro RA, Reisch R, et al. Virtual reality system for planning minimally invasive neurosurgery. Technical note. J Neurosurg. 2008;108:382-94.

12. Wurm G, Lehner M, Tomancok B, et al. Cerebrovascular biomodeling for aneurysm surgery: simulation-based training by means of rapid prototyping technologies. Surg Innov. 2011;18:294-306.

13. Kimura T, Morita A, Nishimura K, et al. Simulation of and training for cerebral aneurysm clipping with 3-dimensional models. Neurosurgery. 2009; 65:719-25. discussion 725-716.

14. Erbano BO, Opolski AC, Olandoski M, et al. Rapid prototyping of threedimensional biomodels as an adjuvant in the surgical planning for intracranial aneurysms. Acta Cir Bras. 2013;28:756-61.

15. Muller A, Krishnan KG, Uhl E, et al. The application of rapid prototyping techniques in cranial reconstruction and preoperative planning in neurosurgery. J Craniofac Surg. 2003:14:899-914.

16. Hopf NJ, Stadie A, Reisch R. Surgical management of bilateral middle cerebral artery aneurysms via a unilateral supraorbital key-hole craniotomy. Mini Invasive Neurosurg. 2009;52:126-31.

17. Gupta SK. Surgical management of giant intracranial aneurysms: a neurosurgeon's perspective. Neurol India. 2015;63:136-7.

18. Namba K, Higaki A, Kaneko N, et al. Microcatheter shaping for intracranial aneurysm coiling using the 3-dimensional printing rapid prototyping technology: preliminary result in the first 10 consecutive cases. World Neurosurg. 2015;84:178-86.

19. Abla AA, Lawton MT. Three-dimensional hollow intracranial aneurysm models and their potential role for teaching, simulation, and training. World Neurosurg. 2015;83:35-6.
20. Khan IS, Kelly PD, Singer RJ. Prototyping of cerebral vasculature physical models. Surg Neurol Int. 2014;5:11.

21. Ionita CN, Mokin M, Varble $N$, et al. Challenges and limitations of patientspecific vascular phantom fabrication using 3D Polyjet printing. Proc SPIE Int Soc Opt Eng. 2014;9038:90380M.

22. Mashiko T, Otani K, Kawano R, et al. Development of three-dimensional hollow elastic model for cerebral aneurysm clipping simulation enabling rapid and low cost prototyping. World Neurosurg. 2015;83:351-61.

23. Chueh JY, Wakhloo AK, Gounis MJ. Neurovascular modeling: small-batch manufacturing of silicone vascular replicas. AJNR Am J Neuroradiol. 2009; 30:1159-64.

\section{Submit your next manuscript to BioMed Central and we will help you at every step:}

- We accept pre-submission inquiries

- Our selector tool helps you to find the most relevant journal

- We provide round the clock customer support

- Convenient online submission

- Thorough peer review

- Inclusion in PubMed and all major indexing services

- Maximum visibility for your research

Submit your manuscript at www.biomedcentral.com/submit
Biomed Central 